\title{
The Importance-Weights Determination of the Safety Factors of Fishing Ports in Zhuhai via the AHP Method
}

\author{
Qiyou Wang ${ }^{1, a}$, Yutian Wang ${ }^{2, b}$, Huaguo $\mathrm{Li}^{3, \mathrm{c}}$ and Shuo Yang ${ }^{4, \mathrm{~d}}$ \\ 'Department of Shipping Engineering, Guangzhou Maritime University, Guangzhou 510725, China. \\ ${ }^{2}$ School of Accountancy, Shandong University of Finance and Economics, Jinan 250014, China. \\ ${ }^{3}$ Guangdong Fishery Administration Corps Zhuhai Detachment, Zhuhai 519000, China. \\ ${ }^{4}$ School of Electronics and Information Technology, Sun Yat-sen University, Guangzhou 510006 , \\ China.

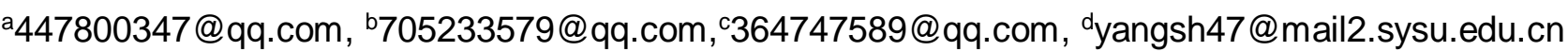

Keywords: Fishing harbor safety factors, maritime administration and Port operation.

\begin{abstract}
The importance-weights determination (IWD) of the safety factors of fishing ports is a meaningful work, because it can be helpful for relevant departments to determine the focus of work and adopt proper measures. But it is an intrinsically complex process as well, for it relates to many fields (e.g., maritime transport management, port operations, etc.) with multiple criteria. In this paper, the Analytic Hierarchy Process (AHP) method, a commonly used decision analysis method, is utilized to make the IWD of Zhuhai's fishing ports safety factors. The IWD problem is greatly simplified and more valid with the AHP method, and through the consistency verification, the result effectively indicates the prioritizing order of all the safety factors.
\end{abstract}

\section{Introduction}

Zhuhai, located at the south-west bank of the Pearl River estuary facing the South China Sea, is one of the earliest four Special Economic Zones in China as well as one of the economically fastest growing areas [1]. With its geographical advantage, Zhuhai possesses a number of excellent fishing ports and islands (e.g., Xiangzhou Fishing Port, Wanshan Island, etc.), and fishery has always been an important industry in Zhuhai [1]. However, due to the impacts of the environment and fishing vessels and so on, accidents related to safety have occasionally happened in these years. In order to find out the safe production situation of fishing port in Zhuhai and take timely rectification of the security issues, Guangdong Fishery Administration Corps Zhuhai Detachment entrusted Guangzhou Maritime University a project (with the project number being 20160211) to investigate the Zhuhai fishing ports safety production. This paper is conducted based on the data originated from the project.

As we know, the factors that affect the safety production of a fishing port are of great complexity. Basically, they can be divided into four main aspects, i.e., fisherman, fishing vessel, fishing port and management, and each of them is followed by several sub-criteria. After extensive work and investigation, the hierarchy model of this problem is structured in Fig. 1. As we can see from Fig. 1, with multilayer criteria and various impact factors, it is intangible and almost impossible to determine the importance-weight (i.e., IWD) of these factors at a time. But via making pairwise comparisons [2-4], AHP method can derive the IWD in an intuitive way [2]. Besides, based on the IWD of this problem, some constructive advice is given at the end of this paper.

It is worth mentioning that the remainder of this paper is organized into four sections. Section II further introduces the AHP method; AHP method is applied in IWD problem of the safety factors in Zhuhai's fishing ports and the result is obtained in Section III; Section IV draws a conclusion and gives several suggestions. 


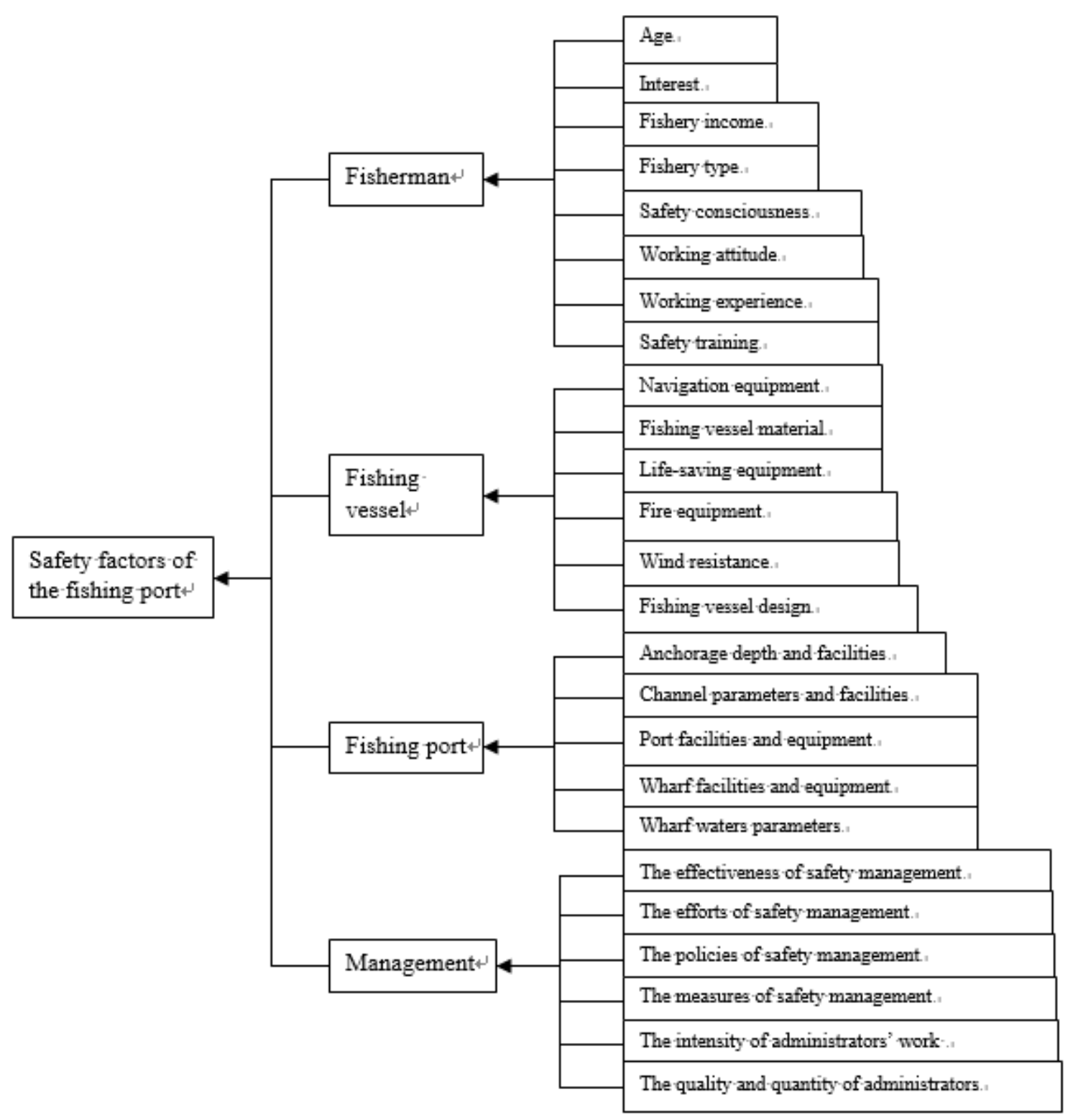

Figure 1 . Hierarchy model of safety factors.

\section{AHP Method Description}

AHP method was firstly proposed by Saaty [2-7]. It is an analytical method based on both mathematics and psychology for the decision making of perplex problems [5], and it has been successfully employed in many cases (e.g., major policy decisions, strategic planning, marketing applications, etc.) [8-11]. A brief discussion about AHP is provided in the previous section. In this section, the details on how to employ AHP to practical problems are presented.

\subsection{Determining The Pairwise Comparisons Matrix Based The Hierarchy Model.}

For a long time, people have been concerned about making the decisions or measurements simultaneously among various alternatives. These decisions or measurements are always intangible and subjective [3]. Take Zhuhai fishing ports problem for instance, as shown in the hierarchy model, it may not be easy to quantify all the factors under different criteria and make a ranking of their importance-weights, but it is relatively easy to make a pairwise comparison between two elements according to homogeneity. Virtually, pairwise comparison is the key and fundament in the use of APH [3].

In practice, we firstly construct the comparisons matrix $\mathbf{A}$ (or say, the judgment matrix) of the main criteria. As shown in Eq. (1), the element of $\mathbf{A}, a_{i j}=w_{i} / w_{j}$, is the relative importance of the $i t h$ factor compared with the $j t h$ factor in the main criteria with respect to the focus. The value of $a_{i j}$ may vary from $1 / 9$ to 9/1 [3,5], where 1/9 
means the $i t h$ factor is extreme unimportant compared with the $j$ th one while $9 / 1$ means extreme important. The order of matrixA, $n$ should be the same as the number of the factors in this level of criteria. Therefore, only $n(n-1) / 2$ comparisons are needed for constructing comparisons matrix $\mathbf{A}$ [3], because $a_{j i}=1 / a_{i j}$, and $\mathbf{A}$ should be a positive reciprocal matrix with the diagonal elements being 1 . As for the comparisons matrixes of the sub-criteria, the process of construction is quite the same, and the number of them depends on how many groups there are among the sub-criteria.

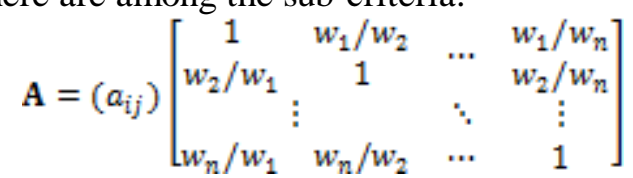

\subsection{Deriving The Local Priorities And Judging The Consistence.}

Once the comparison matrixes are all obtained, based on the AHP method, the local priorities of specific homogeneous factors can be determined by using the principle eigenvalue technique as presented in Eq. (2).

$$
\left(\mathrm{A}-\lambda_{\max } \mathrm{I}\right) \mathbf{q}=0 \text {, }
$$

where $\lambda_{\max }$ is the largest eigenvalue of $\mathbf{A} ; \mathbf{I}$ is the n-order identity matrix; $\mathbf{q}$ is the eigenvector corresponding to $\lambda_{\max }$, and when after $\mathbf{q}$ normalized to sum up to one, it can be the local priorities of a group of factors. Eigenvalues can be easily obtained using MATLAB routine eig [12].

However, if there are many unacceptable inconsistencies in the comparison matrixes, the priorities determined by $\mathbf{q}$ cannot be accepted. Therefore, Saaty provides a way to verify the consistency of our estimation. Firstly, the consistency index which is usually called CI should be calculated by $\mathrm{CI}=\left(\lambda_{\max }-n\right) /(n-1)$. Secondly, the consistency of the comparison matrix can be obtained by a measure called consistency ratio (CR), formulated as: $\mathrm{CR}=\mathrm{CI} / \mathrm{RI}$, where RI represents the average random consistency index which is derived from the average of 500 randomly generated comparison matrixes' consistency indexes. Specifically, the RI of different order $n$ is shown in Table 1 . If $\mathrm{CR}$ is equal to or less than 0.10 , that illustrates that the comparison matrix is of satisfying consistency, or the comparison should be revised and amended.

\subsection{Deriving The Aggregated Priorities With Respect To The Focus.}

In previous subsections the consistent local priorities have been obtained. In order to get the ranking of all the factors with respect to the same focus, the local priorities have to be aggregated. Assuming that $P_{i}$ is one of the impact factors in the lowest criteria level of the hierarchical structure, and the importance-weights of $P_{i}$ for the higher level criteria are $b_{i l}, b_{i 2}, \ldots, b_{i n}$, respectively, and the local priorities are $q_{1}, q_{2}, \ldots, q_{n}$, respectively. Therefore, the importance -weight of $P_{i}$ to the focus (or say, the aggregated priority of $P_{i}$ ) should be calculated as: $\sum_{k=1}^{n} b_{i k}$ " $q_{k}$. Since each of the local priorities is scaled to sum up one, the aggregated priorities $P$ is the same as well.

Table 1 . The average random consistency index.

\begin{tabular}{ccccccccccc}
\hline Order $n$ & 1 & 2 & 3 & 4 & 5 & 6 & 7 & 8 & 9 & 10 \\
\hline RI & 0.00 & 0.00 & 0.58 & 0.90 & 1.12 & 1.24 & 1.32 & 1.41 & 1.45 & 1.49 \\
\hline
\end{tabular}

\section{AHP Method Applied To The Iwd Of Safety Factors In Zhuhai'S Fishing Ports Problem}

Based on the AHP method discussed in the previous section, it can be easily applied to the fishing ports problem in Zhuhai. After discussions with the relevant departments and field research as well as questionnaires, the comparison matrixes of the importance-weights (with three valid digits) and their $\mathrm{CR}$ corresponding to the hierarchy model are determined in Table 2-6 (the names of many factors are abbreviated in order that they can fit in the table). All they $\mathrm{CR}$ are far less than one, which means the comparison matrixes are consistent. For a better comprehension, the aggregated priorities of the importance-weights are presented in Fig. 2.

Table 2. The pairwise comparison matrix for the criteria corresponding to Fig.1.

\begin{tabular}{cccccc}
\hline & Fisherman & Fishing vessel & Fishing port & Management & Weights \\
\hline Fisherman & 1 & 2 & 3 & 5 & 0.477 \\
Fishing vessel & $1 / 2$ & 1 & 2 & 3 & 0.270 \\
Fishing port & $1 / 3$ & $1 / 2$ & 1 & 3 & 0.174 \\
Management & $1 / 5$ & $1 / 3$ & $1 / 3$ & 1 & 0.080 \\
Consistency ratio $(\mathrm{CR})=0.022$ & & & & \\
\hline
\end{tabular}


Table 3. The pairwise comparison matrix for the sub-criteria under the criteria fisherman corresponding to Fig.1.

\begin{tabular}{|c|c|c|c|c|c|c|c|c|c|}
\hline & Age & Inter. & $\begin{array}{l}\text { Fish. } \\
\text { inc. }\end{array}$ & $\begin{array}{l}\text { Fish. } \\
\text { type }\end{array}$ & $\begin{array}{l}\text { Saf. } \\
\text { consc. }\end{array}$ & $\begin{array}{l}\text { Work. } \\
\text { attit. }\end{array}$ & $\begin{array}{l}\text { Work. } \\
\text { exp. }\end{array}$ & $\begin{array}{l}\text { Saf. } \\
\text { Train. }\end{array}$ & Weights \\
\hline Age & 1 & 1 & 2 & $1 / 2$ & $1 / 7$ & $1 / 4$ & $1 / 5$ & $1 / 3$ & 0.043 \\
\hline Inter. & 1 & 1 & 1 & $1 / 2$ & $1 / 8$ & $1 / 3$ & $1 / 6$ & $1 / 3$ & 0.039 \\
\hline Fish. inc. & $1 / 2$ & 1 & 1 & $1 / 3$ & $1 / 9$ & $1 / 5$ & $1 / 7$ & $1 / 4$ & 0.030 \\
\hline Fish. type & 2 & 2 & 3 & 1 & $1 / 4$ & $1 / 2$ & $1 / 2$ & $1 / 3$ & 0.078 \\
\hline Saf. consc. & 7 & 8 & 9 & 4 & 1 & 2 & 2 & 3 & 0.322 \\
\hline Work. attit. & 4 & 3 & 5 & 2 & $1 / 2$ & 1 & 1 & 2 & 0.168 \\
\hline Work. exp. & 5 & 6 & 7 & 2 & $1 / 2$ & 1 & 1 & 2 & 0.195 \\
\hline Saf. train. & 3 & 3 & 4 & 3 & $1 / 3$ & $1 / 2$ & $1 / 2$ & 1 & 0.125 \\
\hline \multicolumn{10}{|c|}{$\begin{array}{l}\text { Consistency ratio } \\
(\mathrm{CR})=0.016\end{array}$} \\
\hline \multicolumn{10}{|c|}{$\begin{array}{l}\text { Table 4. The pairwise comparison matrix for the sub-criteria under the criteria fishing vessel } \\
\text { corresponding to Fig.1. }\end{array}$} \\
\hline & & $\begin{array}{l}\text { Javig. } \\
\text { quip. }\end{array}$ & $\begin{array}{l}\text { Fish. ves. } \\
\text { Mater. }\end{array}$ & & $\begin{array}{l}\text { Life-sav. } \\
\text { equip. }\end{array}$ & $\begin{array}{l}\text { Fire } \\
\text { equip. }\end{array}$ & $\begin{array}{l}\text { Wind } \\
\text { resist. }\end{array}$ & $\begin{array}{l}\text { Fish. ves. } \\
\text { Des. }\end{array}$ & Weights \\
\hline Navig. equip. & & 1 & 2 & & $1 / 3$ & 3 & $1 / 4$ & 3 & 0.122 \\
\hline $\begin{array}{c}\text { Fish. ves. } \\
\text { Mater. }\end{array}$ & & $1 / 2$ & 1 & & $1 / 4$ & 4 & $1 / 5$ & 1 & 0.082 \\
\hline $\begin{array}{l}\text { Life-sav. } \\
\text { equip. }\end{array}$ & & 3 & 4 & & 1 & 7 & $1 / 2$ & 5 & 0.277 \\
\hline Fire equip. & & $1 / 3$ & $1 / 4$ & & $1 / 7$ & 1 & $1 / 9$ & 1 & 0.039 \\
\hline Wind resist. & & 4 & 5 & & 2 & 9 & 1 & 8 & 0.428 \\
\hline Fish. ves. des. & & $1 / 3$ & 1 & & $1 / 5$ & 1 & $1 / 8$ & 1 & 0.052 \\
\hline
\end{tabular}

As can be seen from Fig. 2, the importance-weights of several safety factors are significantly higher, such as safety consciousness (the highest), wind resistance, work experience, etc. That is a good reminder for the government to take appropriate measures.

Table 5. The pairwise comparison matrix for the sub-criteria under the criteria fishing port corresponding to Fig.1.

\begin{tabular}{ccccccc}
\hline & $\begin{array}{c}\text { Anch. dep. } \\
\text { and facil. }\end{array}$ & $\begin{array}{c}\text { Chann. param. } \\
\text { and facil. }\end{array}$ & $\begin{array}{c}\text { Port facil. } \\
\text { and equip. }\end{array}$ & $\begin{array}{c}\text { Wharf facil. } \\
\text { and equip. }\end{array}$ & $\begin{array}{c}\text { Wharf waters } \\
\text { param. }\end{array}$ & Weights \\
\hline $\begin{array}{c}\text { Anch. dep. and } \\
\text { facil. }\end{array}$ & 1 & 4 & 7 & 2 & 5 & 0.467 \\
$\begin{array}{c}\text { Chann. param. } \\
\text { and facil. }\end{array}$ & $1 / 4$ & 1 & 3 & $1 / 2$ & 2 & 0.143 \\
$\begin{array}{c}\text { Port facil. and } \\
\text { equip. }\end{array}$ & $1 / 7$ & $1 / 3$ & 1 & $1 / 4$ & $1 / 2$ & 0.054 \\
$\begin{array}{c}\text { Wharf facil. } \\
\text { and equip. }\end{array}$ & $1 / 2$ & 2 & 4 & 1 & 3 & 0.247 \\
$\begin{array}{c}\text { Wharf waters } \\
\text { param. }\end{array}$ & $1 / 5$ & $1 / 2$ & 2 & $1 / 3$ & 1 & 0.088 \\
$\quad$ Consistency ratio (CR)=0.011 & & & & & \\
\hline
\end{tabular}


Table 6. The pairwise comparison matrix for the sub-criteria under the criteria management corresponding to Fig. 1.

\begin{tabular}{|c|c|c|c|c|c|c|c|}
\hline & $\begin{array}{c}\text { The effect. } \\
\text { of saf. } \\
\text { manag. }\end{array}$ & $\begin{array}{l}\text { The eff. of } \\
\text { saf. manag. }\end{array}$ & $\begin{array}{l}\text { The pol. of } \\
\text { saf. manag. }\end{array}$ & $\begin{array}{l}\text { The meas. } \\
\text { of saf. } \\
\text { manag. }\end{array}$ & $\begin{array}{l}\text { The intens. } \\
\text { of admin. } \\
\text { work }\end{array}$ & $\begin{array}{l}\text { The qual. } \\
\text { and quant. of } \\
\text { admin. }\end{array}$ & Weights \\
\hline $\begin{array}{l}\text { The effect. } \\
\text { of saf. } \\
\text { manag. }\end{array}$ & 1 & 5 & 5 & 4 & 7 & 3 & 0.455 \\
\hline $\begin{array}{l}\text { Fish. ves. } \\
\text { Mater. }\end{array}$ & $1 / 5$ & 1 & 1 & $1 / 2$ & 2 & $1 / 3$ & 0.081 \\
\hline $\begin{array}{l}\text { The pol. of } \\
\text { saf. manag. }\end{array}$ & $1 / 5$ & 1 & 1 & $1 / 2$ & 2 & $1 / 2$ & 0.087 \\
\hline $\begin{array}{l}\text { The meas. of } \\
\text { saf. manag. }\end{array}$ & $1 / 4$ & 2 & 2 & 1 & 2 & $1 / 2$ & 0.129 \\
\hline $\begin{array}{l}\text { The intens. } \\
\text { of admin. } \\
\text { work }\end{array}$ & $1 / 7$ & $1 / 2$ & $1 / 2$ & $1 / 2$ & 1 & $1 / 3$ & 0.054 \\
\hline $\begin{array}{l}\text { The qual. } \\
\text { and quant. of } \\
\text { admin. } \\
\text { Consister }\end{array}$ & $\begin{array}{l}1 / 3 \\
\text { ratio (C }\end{array}$ & $\begin{array}{r}3 \\
.016\end{array}$ & 2 & 2 & 3 & 1 & 0.194 \\
\hline
\end{tabular}

\section{Conclusion}

In this paper, the IWD problem of safety factors of fishing ports in Zhuhai has been investigated via AHP method. Based on the data from the project, APH method has been carried out step by step. Through combining all the data from the comparison matrixes, the aggregated result has been obtained. According to this result (as shown in Fig. 2), the following suggestions should be proposed:

- Strengthen publicity and education, improve fishermen safety awareness

- Focus on the upgrading of the fishing vessels

- Improve the quality and level of management

- Upgrade the infrastructures of the fishing ports

We hope these suggestions highlighted above will help the related government department in prioritizing their fishing port management plan and in allocating the budget more reasonably.

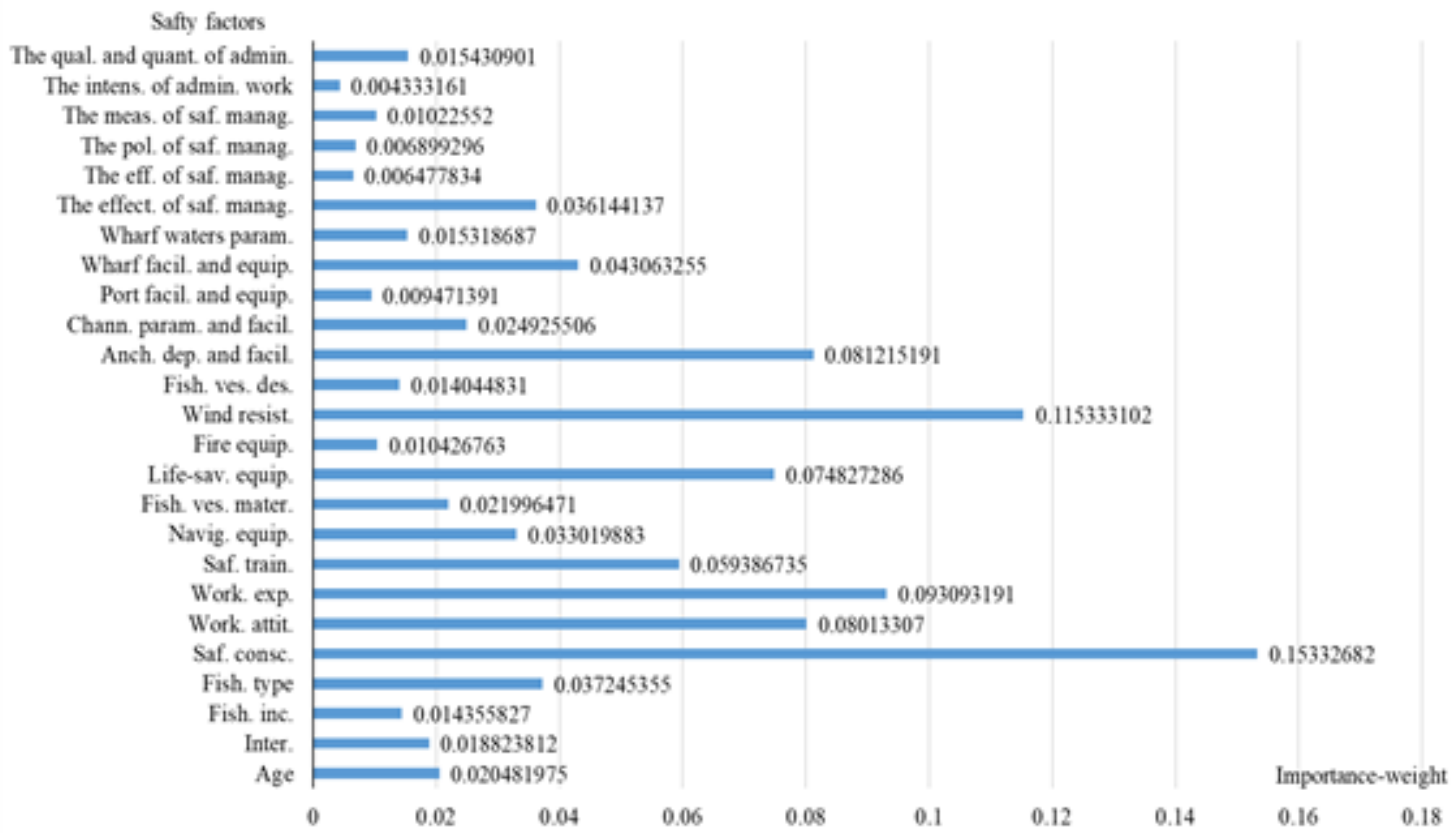

Figure 2. The aggregated priorities of the importance-weights. 


\section{Acknowledgments}

This work was financially supported by the Project of Study on Risk Assessment of Fishing Ports in Zhuhai (with number 20160211). Besides, Qiyou as well as the coauthors of this paper would like to thank the cooperation of the staff in Guangdong Fishery Administration Corps Zhuhai Detachment and the fishermen of the fishing areas in Zhuhai.

\section{References}

[1]. N. Sheng, U.W. Tang, Zhuhai, Cities. 32 (2013) 70-79.

[2]. R. Raman than, A note on the use of the analytic hierarchy process for environmental impact assessment, Math. Modell. 63 (2001) 27-35.

[3]. R.W. Saaty, The analytic process-what it is and how it is used, J. Environ. Manage. 9 (1987) 161-176.

[4]. T.L. Saaty, Decision-making with the AHP: Why is the principal eigenvector necessary, Eur. J. Oper. Res. 145 (2003) 85-91.

[5]. M. Kurttila, M. Pesonen, J. Kangas, M. Kajanus, Utilizing the analytic hierarchy process (AHP) in SWOT analysis - a hybrid method and its application to a forest-certification case, for. Pol. Econ. 1 (2000) 41-52.

[6]. M.T. Escobar, J. Aguarón, J.M. Moreno-Jiménez, A note on AHP group consistency for the row geometric mean periodization procedure, Eur. J. Oper. Res. 153 (2004) 318-322.

[7]. R. Aull-Hyde, S. Erdogan, J.M. Duke, An experiment on the consistency of aggregated comparison matrices in AHP, Eur. J. Oper. Res. 171 (2006) 290-295.

[8]. Y. Wind, T.L. Saaty, Marketing applications of the analytic hierarchy process, Manage. Sci. 26 (1980) 641-658.

[9]. Y. Wind, An analytic hierarchy process based approach to the design and evaluation of a marketing driven business and corporate strategy, Math. Modell. 9 (1987) 285-291.

[10]. J.P. Shim, Bibliographical research on the analytic hierarchy process (AHP), Socio-Econ. Plan. Sci. 23 (1989) 161-167.

[11]. F. Elkarni, I. Mustafa, Increasing the utilization of solar energy technologies (SET) in Jordan: Analytic Hierarchy Process, Energy Pol. 21 (1993) 978-984.

[12]. D.J. Higham, N.J. Higham, MATLAB Guide, Soc. Indust. Appl. Math. Pennsylvania, USA, 2000. 